\title{
TRÊS ARTIGOS SOBRE A ACADIE
}

\author{
Dilma Castelo Branco Diniz*
}

Resumo: Este trabalho trata de três artigos do historiador francês, Émile Lauvrière, sobre a Acadie, a mais antiga colônia francesa da América do Norte, publicados na Revue de l'Amérique latine, em 1924. Nos dois primeiros textos, o autor conta a história da colônia, desde sua criação até a expulsão definitiva dos acadianos pelos ingleses e sua dispersão em várias regiões da América. No último artigo, Lauvrière revela a existência de diversos grupos acadianos atuantes no Canadá e nos Estados Unidos e comenta sobre a situação do Canadá - país dividido entre anglófonos e francófonos - propondo uma maior integração entre os países da América Latina. De 1924 até hoje, houve grandes mudanças: os habitantes do Québec têm as mesmas oportunidades e o mesmo nível de vida que os canadenses das outras províncias, e o povo acadiano cultiva e mantém viva sua herança cultural.

Les Acadiens sont un peuple, et un peuple est plus fort qu'un Pays. Un Pays est une institution, mais un peuple est plus fort qu'une institution, car il a une âme, il a des rêves, il est vivant $(. . .)^{1}$

Antonine Maillet

* Universidade Federal de Minas Gerais/CNPq.

1 "Os acadianos são um povo, e um povo é mais forte que um País. Um País é uma instituição, mas um povo é mais forte que uma instituição, porque ele tem alma, tem sonhos, está vivo (...). ”Antonine Maillet é uma escritora acadiana. Disponível em: <http://cyberacadie.com>. Acesso em: 23 out. 2008. 
Perturba-me o inquietante espetáculo que apresentam o excesso de memória aqui, o excesso de esquecimento acolá, sem falar da influência das comemorações e dos erros de memória - e de esquecimento. A idéia de uma política da justa memória é, sob esse aspecto, um de meus temas cívicos confessos.

Paul Ricœur. A memória, a bistória, o esquecimento, p. 17.

No Brasil, e mesmo na América do Sul, a história da Acadie, a mais antiga colônia francesa na América do Norte, é quase desconhecida. Esse fato suscitou meu interesse por três artigos do historiador francês Émile Lauvrière, publicados na Revue de l'Amérique latine, em 1924, sob o título de "L'Acadie et l'Amérique latine". Nesse mesmo ano, Lauvrière publicara o livro La tragédie d'un peuple ${ }^{2}$ sobre a história dos acadianos.

Convém, em primeiro lugar, situar a referida revista. Publicada em Paris de 1922 a 1932, a Revue de l'Amérique latine foi testemunha de uma intensa atividade franco-latino-americana. Revista mensal, remonta ao antigo Bulletin de l'Amérique latine, fundado em 1910, sob o patrocínio do Groupement des Universités et Grandes Écoles de France, para as relações com a América Latina. Publica estudos de escritores, cientistas e políticos franceses, hispanoamericanos, canadenses e brasileiros sobre a América Latina e suas relações com a França; apresenta traduções de romances, contos, poemas e ensaios de escritores latino-americanos; suas crônicas, numerosas e variadas, resumem a vida intelectual, artística, econômica e social de todo o continente latino da América. Inserida numa ideologia política "latina" e conservadora, de modo geral, revela um gosto mais clássico. Mas, voltemos aos citados artigos.

Em março, abril e maio de 1924, Émile Lauvrière publica três artigos intitulados "L'Acadie et l'Amérique latine", textos que tratam das relações entre os habitantes da primeira colônia

${ }^{2}$ LAUVRIÈRE. La tragédie d'un peuple, $1924 \mathrm{~d}$. 
francesa da América e os outros latino-americanos. No primeiro texto, ${ }^{3}$ o autor faz um resumo da história da Acadie, a primeira das colônias francesas da América, mais antiga que o próprio Canadá. Começa por sua localização geográfica:

Sur la carte vous voyez au sud de la Terre Neuve, une île, le Cap Breton, et une presqu'île, la NouvelleÉcosse, et un arrière pays, le Nouveau-Brunswick. Toutes ces provinces maritimes du Canada actuel constituèrent plus ou moins l'Acadie. ${ }^{4}$

Em seguida, comenta sobre as riquezas da região: terras naturalmente fecundas, cobertas de florestas imensas onde havia muita caça, e também muitos peixes, tanto no mar quanto nos rios e lagos. Traça um painel histórico da exploração e colonização do território, citando diversos exploradores, mas insiste que foram os "latinos", principalmente os franceses, os primeiros a chegar, bem antes dos ingleses. Guiado por Samuel de Champlain, Pierre du Guâ, sieur de Monts, estabelece, em 1604, uma colônia chamada Sainte-Croix (entre o Maine atual e o Canadá), mas não consegue êxito. Foi no ano seguinte que fundou com sucesso a "habitation du Port-Royal" (a Annapolis atual da Nova-Escócia), a primeira cidade da América do Norte, já que Québec, no Canadá e Jamestown, na Virgínia, são de $1607,{ }^{5}$ New-Plymouth de 1620, Salem de 1628 e Boston de 1630. Dessa maneira, foi criada a primeira colônia da Nouvelle-France, isto é, a primeira das colônias europeias nessas regiões setentrionais da América.

\footnotetext{
${ }^{3}$ LAUVRIÈRE. L'Acadie et l'Amérique latine (I), p. 193-202.

4 "No mapa, vê-se ao sul da Terra Nova, uma ilha, o Cabo Breton, e uma península, a Nova-Escócia e uma região afastada da costa, o Novo-Brunswick. Todas essas províncias marítimas do Canadá atual constituíram mais ou menos a Acádia." Cf. LAUVRIÈRE. L'Acadie et l'Amérique latine (I), p. 193. (A tradução é de minha autoria, bem como as que se seguem.)

${ }^{5}$ Parece que aqui houve um engano, já que, oficialmente, a data da fundação de Québec é 1608. No ano de 2008, foi celebrado o quarto centenário da cidade.
} 
O autor passa então a descrever a Acadie. Explica que não tem a intenção de refazer nem mesmo de resumir sua história, mesmo sabendo que é muito pouco conhecida e complexa em seus perpétuos recomeços e suas inextricáveis perturbações políticas; deseja somente mostrar o interesse humano, trágico mesmo, que ela apresenta aos leitores hispano-americanos.

Pierre du Guâ, sieur de Monts, tinha apenas 120 soldados voluntários, mas "todos desejosos de participar da glória de tão bela e generosa empresa", ${ }^{6}$ entretanto perde 36, em Sainte-Croix, de um mal desconhecido: "o escorbuto". Além disso, sofreram com um inverno incrivelmente rigoroso. Émile Lauvrière revela ainda que a fundação de Port-Royal pelo Sieur de Poutrincourt ${ }^{7}$ nos é contada por seu companheiro e colaborador, Marc Lescarbot, do Parlamento de Paris, com uma verve bem francesa que não exclui nem o zelo cristão nem os métodos práticos. Tratava-se de uma colônia agrícola: plantavam diversos grãos, hortaliças e frutas, além de criar vários animais domésticos. Outra característica importante dessa colonização francesa: havia uma atitude de muito respeito, da parte dos colonos, em relação aos indígenas.

Mas diversas intrigas - de comerciantes, de padres e da Corte - provocaram a vinda de um bandido da Virgínia, Samuel Argall, em 1613. Em plena paz, esse homem veio destruir as colônias nascentes de Saint Sauveur e de Port Royal, que não tinham armas, já que viviam sem suspeitas. Mesmo assim, alguns franceses persistiram, recolhidos e sustentados pelos selvagens que viviam na região e que eram seus amigos. Entre eles, o filho de Poutrincourt e um aventureiro, Charles Latour. Esse grupo apelou para a França, que não os ajudou. Jacques d'Angleterre, então, aproveitou as divergências de opinião da França para tentar fundar, sobre as ruínas da Acadie, a Nova Escócia. Entre as pessoas que o ajudaram nessa empresa estava o traidor Charles Latour, que,

${ }^{6}$ Cf. LAUVRIÈRE. L'Acadie et l'Amérique latine (I), p. 195.

${ }^{7}$ M. de Poutrincourt foi sócio de M. Pierre du Guâ, sieur de Monts. 
sendo bom pescador em águas turbulentas, fazia-se cumular de favores por amigos e inimigos, ou seja, franceses e ingleses.

Felizmente, Richelieu intervém. Confiante com os tratados de Suze e de Saint-Germain, ele corta pela raiz as intrigas e duplicidades dos Stuarts enviando à colônia seu próprio primo, Isaac de Razilly, herói do mar, vencedor de La Rochelle, comendador de Malta, etc. “'Não vejo outro objetivo', escreve ele a Richelieu, 'senão a glória de Deus, a grandeza do Rei, o serviço de Vossa Eminência'." A Nouvelle France está em boas mãos: Port-Royal, Saint-Jean, Pentagouët são ocupadas; La Hève é colonizada. "Trezentos homens de elite (...) não têm outra paixão senão povoar o país (...) O vício não reina nesse lugar; a caridade e a amizade existem aí sem constrangimento (...) Os selvagens se submetem de sua própria vontade a todas as leis, tanto humanas quanto divinas." Tudo vai muito bem, quando, subitamente, Razilly morre, em 1639. Entretanto, isso não foi um obstáculo, pois Charles d'Aulnay, seu colaborador, homem de coragem, enérgico e experiente, compromete-se a continuar a obra tão gloriosamente iniciada. Mas, desamparado, ele esgota seu tempo, forças e recursos numa luta desesperada contra o traidor Latour, que é sustentado, perfidamente, pelos Puritanos da Nova Inglaterra, hostis a toda colonização francesa na América. Ele acaba triunfando, mas também morre tragicamente nos pântanos de Port-Royal, quando tentava construir um dique, em 1650. A pobre Acadie estava sem sorte.

Depois da morte de Charles d'Aulnay, houve anarquia e guerra. Aproveitando a situação instável, os ingleses apoderaramse do território. Em 1654, Cromwell lança uma expedição que, sem disparar um tiro, toma posse de Pentagouët, de Saint-Jean, de Port-Royal e de La Hève. Felizmente, em 1667, o tratado de Breda devolve a Acadie à França, apesar de todos os argumentos da diplomacia inglesa.

${ }^{8}$ Cf. LAUVRIÈRE. L'Acadie et l'Amérique latine (I), p. 198.

${ }^{9}$ Cf. LAUVRIÈRE. L'Acadie et l'Amérique latine (I), p. 198. 
Colbert, um grande amigo das conquistas pacíficas da colonização, estava no governo: não havia mais vice-reis autocratas e impotentes, mas governadores dóceis, dirigidos pelo ativo ministro. Infelizmente, foram muitos: dez em quarenta anos. Ao sábio Colbert, sucede o ousado Louvois. Ao Norte áspero e seguro preferiram os pântanos e miragens da Louisiane. Em vão sucedemse avisos, ameaças, ataques, e, em 1710, sob golpes repetidos, diante de forças dez vezes superiores, a Acadie sucumbe, apesar do heroísmo de seu último defensor. O tratado de Utrecht, em 1713, tira para sempre a Acadie da França.

Com a conquista inglesa, o que acontece com esses acadianos, esses 2.500 bravos camponeses, honestos, laboriosos, prósperos, em suma? Os negociadores e o próprio rei da França não os esquecem nas cláusulas do tratado e nas convenções que se seguem: a eles reservaram o direito de deixar o país com seus bens ou de ficar, com o livre exercício de sua religião. Mas todos os acadianos optaram pela partida, e preferiram mudar-se para as colônias francesas da vizinhança.

No entanto os ingleses, que precisavam deles para os trabalhos da lavoura, fizeram de tudo para retê-los: adulações, medidas dilatórias, proibição de lhes fornecer equipamentos para seus navios. Por fim, proibiram os navios de deixar as águas inglesas, e pior, chegaram a tomar seus navios. Ei-los, portanto, prisioneiros em território inglês. Segue-se um período de guerra e, quando a luta terminou, a cidade inglesa de Halifax estava fundada e bem provida de tropas e navios... Sendo assim, para que manter esses franceses neutros, declarados recalcitrantes? Não seria melhor dar aos colonos ingleses, por pouco mais de nada, suas belas terras, bem preparadas e em pleno rendimento?

Foi assim que, durante dez anos, sem que as vítimas enganadas soubessem, instigados pelos governadores ingleses da Nova Escócia e de Massachusetts, com a cumplicidade cautelosa do governo metropolitano, foram elaborados minuciosos projetos de deportação em massa e de expropriação definitiva. Em 1755, a 
hora parecia favorável: aconteceu então o que se chamou de "le grand dérangement" ou a grande deportação dos acadianos.

Um belo dia de verão, terminada a colheita, uma ordem é dada a toda a população masculina de se reunir nas igrejas, com o fim de resolverem questões agrárias pendentes. Estando todos juntos, logo os soldados fecharam as portas e todos foram declarados prisioneiros em nome do rei: estupor, clamor, lágrimas. As mulheres vêm suplicar por seus pais, maridos e filhos. Dizem que só lhes resta alimentá-los para que não morram de fome. Navios estão ao largo; outros chegam; os homens são embarcados primeiro, pois são considerados perigosos, depois, as mulheres e as crianças. Todos amontoados, famílias separadas, com rações de fome, desprovidos de roupas e do conforto necessário. Em seguida, sob o olhar das vítimas mudas de horror, incendeiam as igrejas, casas, granjas e moinhos. Esse povo vai ser disseminado nas treze colônias inglesas, ao longo do Atlântico e até nos trópicos. Ordens expressas de separar as famílias, de arrancar as crianças dos pais, de explorar todos eles. O que se queria era, evidentemente, a exterminação definitiva desse povo inocente que incomodava. Assunto lúgubre do livro Évangéline, de Longfellow, cuja alma idílica muito atenuou a iniquidade e o horror. ${ }^{10}$

O autor comenta que não vai seguir "esse povo mártir"11 em todas as suas rotas do exílio, nas colônias do sul onde os agrupam aos escravos negros para o trabalho dos arrozais, nas colônias do Norte onde abandonam homens, mulheres e crianças, muitas vezes isolados, a exploradores fanáticos que os roubam, os chicoteiam, os expõem ao pelourinho. Basta dizer que, durante mais de oito anos de torturas físicas e morais, a maior parte dos exilados morreu ou desapareceu para sempre nesse meio hostil.

\footnotetext{
${ }^{10} \mathrm{O}$ tema do "Grand Dérangement" é também evocado em Pélagie-la-Charrette, de Antonine Maillet, romance que recebeu o prêmio Goncourt de 1979. Foi a primeira vez que o Goncourt saiu da França.

${ }^{11}$ Cf. LAUVRIÈRE. L'Acadie et l'Amérique latine (I), p. 201.
} 
Émile Lauvrière lembra ainda que mais de 3.000 acadianos foram deportados das ilhas Royale e Saint-Jean, da Nova Escócia e até mesmo da Virgínia para a França. Lá, foram protegidos e bem tratados: o próprio Rei tomou-os sob sua proteção pessoal, uma política generosa que continuou sob Louis XVI e prosseguiu até 1823.

No segundo artigo, ${ }^{12}$ o autor descreve os diversos estabelecimentos acadianos na América. O primeiro deles interessa particularmente os hispano-americanos. Ao nordeste do estreito de Magalhães, havia um arquipélago deserto que nenhum povo tinha ainda reclamado. Bougainville então atreve-se a instalar aí "ces honnêtes et infortunés citoyens, intelligents et laborieux dont il avait apprécié au Canada même l'inviolable attachement à la France". ${ }^{13}$ Autorizado pelo Rei e por seu ministro, ele leva de SaintMalo, em 1763, duas famílias acadianas (dez pessoas); dois anos depois, outras oitenta e, enfim, mais cinquenta em 1766. Ele os instala em Port Louis, numa grande baía que ele chama de "Baie Française", em homenagem a seu país, enquanto ao arquipélago inteiro, ele dá o nome de Iles Malouines, em homenagem a SaintMalo, sua cidade de partida. Tudo era favorável: o clima frio convinha às pessoas do norte; o trigo e as outras plantas europeias cresciam bem; o gado, pequeno e grande, vivia em liberdade.

Mas surgem olhares invejosos. Desde 1764, o comodoro Byron, avô do poeta, triste herói das demolições de Louisbourg e das deportações acadianas, é enviado a esses lugares longínquos para criar dificuldades aos esforços franceses. Ele permanece ali apenas treze dias, sem desembarcar um só colono, nem declara que são inglesas as ilhas que ele chama de Falkland. Volta em 1766 e opõe seu rudimentar Port-Egmont ao Port-Louis dos franceses, que ameaça de destruição se não houver uma evacuação

\footnotetext{
${ }^{12}$ LAUVRIÈRE, L'Acadie et l'Amérique latine (II), p. 316-327.

13 "Esses honestos e infortunados cidadãos, inteligentes e laboriosos dos quais havia apreciado no Canadá mesmo a inviolável afeição à França." LAUVRIÈRE. L'Acadie et l'Amérique latine (II), p. 316.
} 
imediata. Para evitar um conflito, o medroso governador francês acreditou ser mais sábio reconhecer os pretendidos direitos da Espanha sobre esse arquipélago só colonizado pelos franceses. Depois de gastar muito dinheiro, o pobre Bougainville teve que repatriar em fragatas espanholas os habitantes que não quiseram lá permanecer.

Uma das colônias sobre as quais Choiseul depositou mais esperanças para criar uma Nova França de ultramar foi a Guyane. Infelizmente, vítima de sua ignorância e incompetência, deixouse levar pela megalomania de Turgot, irmão do futuro ministro. Enquanto o comandante Préfontaine queria, sabiamente, iniciar uma colonização em Kourou com apenas cem colonos brancos e trezentos negros, o presunçoso Governador enviou, em alguns meses, mais de dez mil aventureiros de vários países. Foi então grande o desperdiço de dinheiro e de vidas!...

Não se sabe precisar quantos acadianos foram levados nessa terrível aventura, mas uma coisa é certa: a maior parte desses camponeses da América setentrional desconfiaram desde o início dessas miragens de uma América tropical. Os refugiados de SaintPierre-et-Miquelon, mesmo em condições miseráveis e precárias, não se deixaram tentar pelas ofertas vantajosas que lhes foram feitas em nome do Rei. "Un pays si chaud nous coûterait trop cher; jamais nous n'accepterons de quitter ce climat. C'est le sentiment de tout notre monde, si réduit qu'en soit le nombre par la faim, la prison et les mauvais traitements des Anglais." ${ }^{14}$ Não insistiram. Na França, porém, algumas centenas de pessoas foram persuadidas, principalmente em Morlaix, já que se encontram, no recenseamento de Sinnamari (maio de 1765), 138 acadianos; e nos documentos seguintes, está assinalado o retorno de refugiados mais ou menos

14 "Um país tão quente nos custaria caro demais; nunca aceitaremos deixar esse clima. É o sentimento de nosso povo, mesmo assim tão reduzido em número pela fome, prisão e maus-tratos dos ingleses." LAUVRIÈRE. L'Acadie et l'Amérique latine (II), p. 317. 
miseráveis. $\mathrm{O}$ autor entretanto afirma que o governo francês nunca usou de violência nem de força para se desembaraçar de hóspedes às vezes onerosos e incômodos. Ao contrário, a um pedido para se estabelecer em Cayenne, dirigido em $\mathbf{1 7 7 0}$ por numerosos acadianos que haviam ficado sob a dominação inglesa, foi respondido lealmente que "à la suite d'expériences réitérées, il était prouvé que le climat s'opposait à tout peuplement des blancs". ${ }^{15}$ Isso, entretanto, não impediu que se encontrassem, em recenseamentos posteriores a 1900, vários nomes bem acadianos: de Brot, Saunier, Tibodo e Labrador.

Pelo clima quente das Antilhas os acadianos manifestaram a mesma repugnância. Apesar das promessas, foram poucos os acadianos que saíram da França. Apenas alguns de Rochefort passaram para as Iles-sous-le-Vent. Foi necessária toda a crueldade dos ingleses da Nova Inglaterra e da Nova Escócia para induzir um certo número de acadianos a responder ao convite do governador, o conde d'Estaing: pessoas de Nova York transportaram muitas centenas ao porto de Saint-Nicolas em Saint-Domingue, unicamente com o objetivo de espioná-los. O governador de Halifax só consentiu na partida de algumas centenas porque dizia: "O clima dessas regiões é mortal para as pessoas do norte." 16 Infelizmente, era verdade. Das famílias acadianas enviadas a SaintDomingue muitas morreram, segundo um relatório de 5 de agosto de 1782. De qualquer forma, mesmo que muitos tenham sobrevivido nas Antilhas, essa região foi, na maior parte das vezes, um lugar de passagem para eles.

Para onde iriam os acadianos além das Antilhas? Para um belo país francês, que antigamente era louvado pelos missionários e alguns aventureiros das florestas do Novo Mundo: a Louisiane.

\footnotetext{
15 "Depois de reiteradas experiências, ficara provado que o clima se opunha a todo povoamento de brancos." LAUVRIÈRE. L'Acadie et l'Amérique latine (II), p. 318.

${ }^{16}$ LAUVRIÈRE. L'Acadie et l'Amérique latine (II), p. 318.
} 
Nessa região quente, mas fértil e saudável, chegaram desde 1758 pequenos grupos de acadianos que escaparam dos ingleses da Georgia, das Carolines e até de Maryland. Logo depois de terminada a guerra, afluíram às centenas vindos das Antilhas, da Nova Inglaterra ou da Nova Escócia.

Ce n'est plus de centaines que l'on parle, écrit l'ordonnateur Foucault, mais des milliers qui viennent fixer à la Louisiane leur destinée errante depuis dix ans (...) Rien n'est prévu pour recevoir et placer cette peuplade si considérable (...) Pour comble de malheur, ils apportent la petite vérole... Cependant, c'est un devoir de ne pas les abandonner (...) L'humanité et l'honneur de la nation exigent que l'on ait des égards pour ces pauvres gens qui ne sont malheureux que par leur attachement inviolable à la patrie et à la religion. ${ }^{17}$

Foram muito bem recebidos: ganharam remédios, víveres, roupas, terras, gados; alguns se instalaram na margem esquerda do Mississipi (ao sul de Bâton Rouge), terra que recebeu o nome de "Costa dos acadianos", outros, na região rica dos Attakapas e dos Opelousas. Bons cultivadores, logo tiveram sucesso. As notícias espalharam-se e vieram outros da Guyane, de Saint-Pierre et Miquelon e até da França.

Mas, ainda aí, nova infelicidade esperava os acadianos: a Louisiane não era mais francesa. Assim como todo o país ao leste do Mississipi tinha sido entregue à Inglaterra, em 1762, por uma

17 "Não se fala mais de centenas, escreve o ordenador Foucault, mas de milhares que vêm fixar seu destino errante na Luisiana há dez anos (...) Nada está previsto para receber e estabelecer esse povo tão considerável (...) Para o cúmulo da infelicidade, eles trazem a varicela (...) Entretanto é um dever não abandoná-los (...) A humanidade e a honra da nação exigem que se tenha respeito por essa pobre gente que só é infeliz por seu apego inviolável à pátria e à religião." LAUVRIÈRE. L'Acadie et l'Amérique latine (II), p. 319. 
cláusula secreta do tratado de Fontainebleau, todo o país a oeste passara ao domínio da Espanha. Quando, em 1768, o governador Antonio d'Ulloa tomou possessão daquelas terras, uma onda de espanto e dor se alastrou: ele se opôs a certas concessões de terras, impôs outras, reenviou três famílias para a Nova Inglaterra, alugou algumas famílias como escravas para exploradores ingleses. Houve uma revolução em outubro de 1768 e, no ano seguinte, chegou um novo governador espanhol, O'Reilly, que à soberba espanhola juntava o fanatismo irlandês. Dos dezoito chefes da revolta, um tinha um nome acadiano: Doucet. "En 1771, il arriva au Cap (SaintDomingue) un bâtiment chargé de Français de la Louisiane qui abandonnaient leurs terres à cause des vexations espagnoles."18

Para a Louisiane vieram contudo muitos outros acadianos. Depois de negociações iniciadas em 1777, a Corte da Espanha decidiu levar para sua nova colônia todos os acadianos da cidade francesa de Nantes que o desejassem. Em 1785, depois da guerra, 2.500 acadianos vieram de todas as partes da Bretagne e do Poitou. Se a esse número juntarmos os 1.000 a 1.200 já vindos das Antilhas e das colônias inglesas, percebe-se que, nas margens do Mississipi, se reconstituía uma Nouvelle-Acadie.

Só faltava que ela se tornasse outra vez francesa. Em primeiro de outubro de 1800, o tratado de Santo Ildefonso entregava a Louisiane à França. Foi grande a alegria tanto na metrópole quanto na colônia. Mas a felicidade durou pouco!... Pouco tempo depois, Bonaparte, sem navios e sem dinheiro, vendia a Louisiane aos Estados Unidos, para que ela não caísse em mãos inglesas.

Les postes les mieux peuplés, qui se sont toujours distingués par un ardent amour de la France, surtout ceux d'Attakapas et d'Opelousas, (il s'agit bien des

\footnotetext{
18 "Em 1771, chegou ao Cap (Santo Domingo) uma embarcação carregada de franceses da Luisiana que abandonavam suas terras por causa das perseguições espanholas." LAUVRIÊRE. L'Acadie et l'Amérique latine (II), p. 320.
} 
Acadiens), manifestèrent vainement des sentiments peu favorables aux Américains. ${ }^{19}$

A Nouvelle-Acadie do sul, assim como a do norte, teve que se desenvolver sob dominação estrangeira. Mas desenvolveu-se assim mesmo. Estima-se que dos 3.500 a 4.000 acadianos do tempo da cessão definitiva, em 1804, saiu uma população de 30.000 pessoas em 1890 e de 50.000, em 1924, se bem que seja difícil precisar mais, em razão dos numerosos casamentos com franceses e mesmo com americanos.

Emile Lauvrière explica que, de criadores que eram na origem, os Acadiens ou Cadiens, como são chamados, tornaramse agricultores. Pouco a pouco, essas plantações se diversificam e se expandem. Novas técnicas agrícolas são incorporadas e surgem processos científicos de cultura moderna. A juventude, atraída aos centros urbanos, instrui-se e muitas vezes passa a exercer funções comerciais, industriais e liberais. Enfim, a recente exploração de ricos e imensos terrenos petrolíferos em plena terra acadiana tende a transformar o caráter atávico de uma raça que permaneceu até então sociável, hospitaleira, leal em negócios, capaz mesmo de patriotismo francês durante a última guerra. ${ }^{20}$

Convém lembrar que, ao contato com os ianques, mais práticos, arrivistas e muito preocupados com o sucesso material, perdeu-se um pouco de certos particularismos acadianos, como a calma, a sabedoria e o desinteresse. Lauvrière comenta ainda que a influência inglesa aparece sobretudo através do mestre-escola americano e do padre irlandês. A velha língua dos Cadiens, principalmente, é considerada corrompida, já que não é mais escrita nem ensinada, parecendo um "jargon de nègre”. Nesse

\footnotetext{
19 "Os postos mais povoados, que sempre se distinguiram por um amor ardente pela França, sobretudo os de Attakapas e d'Opelousas, (trata-se bem dos acadianos), manifestaram inutilmente sentimentos pouco favoráveis aos americanos." LAUVRIÈRE. L'Acadie et l'Amérique latine (II), p. 320.

${ }^{20}$ Trata-se, naturalmente, da Primeira Guerra Mundial, já que o texto é de 1924.
} 
contexto, os alunos, muito dóceis, têm a inocência de acreditar no professor e não ousam empregá-la.

Émile Lauvrière ainda lembra uma série de acadianos que se distinguiram na Louisiane. São políticos influentes, como diversos governadores, senadores, magistrados e militares que atuaram e ainda atuam em postos-chave nos Estados Unidos. E indaga: esse resto de influência latina no sul da América setentrional vai desaparecer? Por que não criar um Comité FranceAcadie para unir as pessoas na mesma luta nacional levada a efeito nos grupos acadianos do norte? Seria a salvação dos destinos latinos na Louisiane.

$\mathrm{O}$ terceiro artigo $^{21}$ do historiador francês inicia-se com o recenseamento dos diversos grupos acadianos atuantes na Nouvelle-Écosse, no Cap Breton, na Ile du Prince-Edouard (antiga ilha Saint-Jean), nas Iles de la Madeleine, no Labrador laurentien, no Nouveau-Brunswick. Isso sem contar os acadianos do Québec, da Terre-Neuve, da Nouvelle-Angleterre e da Louisiane. Ao todo, a população acadiana se elevaria a meio milhão de pessoas. Tratase, portanto, de uma verdadeira ressurreição.

Mas três males atormentam esse povo que renasce: a emigração que o atrai em direção aos altos salários nos Estados Unidos, a anglicização que se inicia nos pequenos grupos isolados, sobretudo sob a funesta influência do clero irlandês; enfim, a falta de organização social que abandona, por exemplo, os pescadores do Golfo Saint-Laurent à exploração descarada das companhias inglesas. Para esses males, anuncia alguns remédios: um clero ativo e perspicaz, escolas e colégios que educam as classes dirigentes: padres, homens da lei, políticos, profissionais liberais. Para evitar a dispersão dos grupos, os acadianos criaram uma sociedade nacional (L'Assomption), um jornal nacional (L'Evangéline), organizaram uma festa nacional (15 de agosto), assembleias nacionais (sucessivamente em cada grupo) e enfim adotaram uma

${ }^{21}$ LAUVRIÈRE. L'Acadie et l'Amérique latine (III), p. 401-406. 
bandeira nacional ( tricolor com uma estrela de ouro no azul). Também se voltam para a mãe pátria, isto é, a França. Um duplo Comité France-Acadie acabara de se constituir: Section Française com o Marechal Fayolle, Mgr Baudrillart, MM. René Bazin, René Doumic, Gabriel Hanotaux, de l'Académie Française; Section Acadienne com todas as notabilidades eclesiásticas, políticas e outras da Acadie. ${ }^{22}$

Ao se encaminhar para o fim do artigo, o autor pergunta: "Em que tudo isso pode interessar aos ibero-americanos?" O interesse é direto, imediato, intenso, responde logo. O grande perigo que corre todo o Novo Continente é a hegemonia anglosaxônica dos Estados Unidos. Um povo que, em cem anos, passou de cinco milhões a cem milhões de habitantes, tem fatalmente excesso de orgulho e ambição. A superprodução desenfreada e aplicada a recursos inteiramente novos quer a todo custo, pelas vias sinuosas da diplomacia ou pelos bruscos desvios da política, como através da intimidação de uma dupla marinha de comércio e de guerra, garantir, em todo lugar, a venda fácil de mercadorias de toda natureza. Isso pressupõe, naturalmente, a dependência dos mais fracos. Com o poder marítimo seguindo a mercadoria, a política americana torna-se realmente mundial.

$\mathrm{O}$ autor então denuncia: se o imperialismo ianque se opõe cada vez mais, na América, a toda colonização, exploração e influência dos povos europeus, é porque ele quer preservar para si esse imenso mercado, vasto campo de expansão, poderoso controle financeiro e político. A doutrina Monroe, de defensiva que era a princípio, afirma-se cada vez mais agressiva: "A América para os americanos" quer dizer agora "A América para os norteamericanos". Defendendo uma ideologia latina, o autor acrescenta: "O panamericanismo torna-se pansaxonismo." A recente conferência de Santiago do Chile anunciava-se mais ameaçadora que as outras.

${ }^{22}$ LAUVRIÈRE. L'Acadie et l'Amérique latine (III), p. 402. 
Tratava-se, sob aparência benigna, de preparar a transformação de todo o Novo Mundo em uma vasta federação econômica e política, cuja direção estaria de fato em mãos dos Estados Unidos. Dessa maneira os sul-americanos, em inquietude legítima, voltam-se em direção dos povos latinos da Europa. Apelam para a Sociedade das Nações, ${ }^{23}$ da qual os próprios inventores wilsonianos não querem mais suportar os entraves, boa quando muito aos aliados da véspera.

Émile Lauvrière observa então que os povos latinos do sul, sem se voltar para o Velho Continente, podem encontrar nos latinos do norte aliados, e mesmo parentes, vítimas do mesmo mal. Os acadianos e canadenses constituem só um conjunto pequeno de três milhões de pessoas, mas não se pode esquecer de que há nos Estados Unidos um milhão e meio de franco-americanos, solidamente organizados, unidos por uma ativa imprensa francesa.

Comenta ainda que há um conflito crescente entre as duas grandes irmãs saxônicas que disputam, sorrateiramente, o império do mundo. A irmã mais velha da Europa não pode ver com serenidade sua jovem caçula da América tomar-lhe cada vez mais os recursos mundiais, inclusive o petróleo, os mercados da Ásia e sobretudo os da América do Sul e desprezá-la com insolência, na pretensão de roubar-lhe o secular domínio dos mares. ${ }^{24}$ Ainda há outro problema: a lenta desagregação do império britânico. Os domínios ingleses (Canadá, Austrália, África do Sul, Nova Zelândia) assim como os protetorados alógenos (Egito e Índia) não querem mais ouvir falar de governo metropolitano, nem

\footnotetext{
${ }^{23}$ Convém lembrar que a "Sociedade das Nações" ou "Liga das Nações" foi uma organização internacional criada pelo Tratado de Versalhes em 1919, com o papel principal de assegurar a paz mundial. Sua criação foi baseada na proposta de paz enviada pelo presidente estadunidense Woodrow Wilson, em mensagem ao Congresso dos Estados Unidos em 8 de janeiro de 1918. Curiosamente, os Estados Unidos não se tornaram membro do novo organismo.

${ }^{24}$ LAUVRIÈRE. L'Acadie et l'Amérique latine (III), p. 404.
} 
mesmo de tutela diplomática. O bloco britânico divide-se: "O Canadá marcha em direção da independência total”, constata o marechal Fayolle em 15 de setembro de $1921 .{ }^{25}$

Sim, mas atenção! exclama o historiador. O separatismo geral leva à dissolução local: pois há dois Canadás, o Canadá inglês e o Canadá francês, unidos só pelo vínculo federal, por sinal bem fraco! Não é duvidoso pois que se separem, esses irmãos siameses que não se entendem, sendo tão diferentes de humor... diz Lauvrière. ${ }^{26} \mathrm{O}$ grande e gordo irmão caçula do oeste, já fortemente americanizado pelo múltiplo legado ianque (sangue, fé, costumes, capitais, mercadorias, máquinas, etc.) e por sua cultura leiga e materialista, tenderá a um entendimento íntimo com os vizinhos do sul, correndo o risco de uma anexação. Mas o magro irmão mais velho do leste, o Canadá francês, sempre ludibriado e maltratado, sempre perseguido em sua fé e em sua língua, reduzido há mais de um século e meio a uma porção inferior, o que será dele? Uma vez livre do cativeiro, instaurado pela violência de 1763 , não irá com alegria de coração abdicar sua legítima independência entre as mãos brutais de uma maioria intolerante cuja antipatia espontânea vem tanto da raça quanto da língua, das leis e dos costumes, das tradições e aspirações. Não, francês e católico, retomará sem hostilidade cega, certamente, em relação aos aliados da véspera, sem tolo desdenho de interesses comuns, o nobre culto do idealismo francês feito de clareza intelectual e de generosidade sentimental, e se apoiará nos povos de mesma civilização, sejam eles do Velho Mundo ou do Novo. Dessa forma, encontrará naturalmente a união com a harmonia latina dos iberoamericanos, provenientes também tanto da Roma antiga como da Roma cristã.

O autor finalmente pergunta: "a dupla questão acadiana e canadense é portanto indiferente à América Latina?”; "as

\footnotetext{
${ }^{25}$ LAUVRIÈRE. L'Acadie et l'Amérique latine (III), p. 405.

${ }^{26}$ LAUVRIÈRE. L'Acadie et l'Amérique latine (III), p. 405.
} 
poderosas e prósperas nações do sul, há muito emancipadas, devem negligenciar as pobres irmãs do norte ainda mais ou menos subjugadas?"; "não têm elas interesse em ajudá-las?" E continua: que elas as conheçam melhor, que elas aprendam sua história, e não poderão impedir de se dedicar a uma bela causa que lhes é comum. Um novo "pacto de família" deve unir a América Latina dos dois hemisférios. Existe aí um dever étnico ao mesmo tempo que um interesse nacional. ${ }^{27}$

Essa era a situação do Canadá francês em 1924, vista por Émile Lauvrière. Atualmente, as coisas mudaram radicalmente. Desde 1931, a dependência do Canadá aos ingleses foi diminuída, pelo Estatuto de Westminster. Nesses anos, a Grande Depressão já mostrava seus efeitos - desemprego, miséria, fome -, efeitos que apenas terminariam com o início da Segunda Guerra Mundial. Depois de 1945, com o final da guerra, a economia do país continuou a crescer até os dias atuais. Atualmente, o Canadá é considerado um dos países mais ricos do mundo e ninguém o aponta mais como parte da América Latina, que permanece estigmatizada pela pobreza.

Quanto à questão do Canadá francês, o nacionalismo quebequense foi aumentando cada vez mais, chegando ao auge no período da Revolução Tranquila (1960-1966). Nessa época, o partido liberal do Québec, sob a direção de Jean Lesage, chega ao poder e elabora um programa profundamente reformista. Em poucos anos, a província moderniza o conjunto de suas estruturas econômicas, sociais, culturais e seu sistema educacional. A noção de Estado responsável torna-se um conceito-chave para a compreensão do sentido da Revolução Tranquila. Considera-se então que as verdadeiras alavancas do desenvolvimento econômico devem ser confiadas a instituições estatais, o que favorecia o pleno desabrochar da sociedade quebequense. Na década de 1960, cresce o sentimento de consciência nacional que

${ }^{27}$ LAUVRIÈRE. L'Acadie et l'Amérique latine (III), p. 406. 
deixa sua marca em todos os setores de atividade, a começar pelo domínio da cultura. Desde essa época houve uma mudança de identidade: não se dizia mais "canadense francês" mas "quebequense". A mudança radical dos valores sociais, familiares e religiosos permitiu que o Québec entrasse completamente na modernidade. ${ }^{28}$

Hoje os habitantes do Québec têm as mesmas oportunidades e o mesmo nível de vida que os canadenses das outras províncias. ${ }^{29}$ O Canadá ainda permanece unido, apesar de ter havido algumas tentativas de independência do Québec, através de referendos. E a ameaça de anexação aos Estados Unidos, suposta pelo historiador francês em 1924, parece totalmente descartada, embora os dois países tenham acordos comerciais importantes. Outro dado relevante: o país é fortemente influenciado pelos numerosos imigrantes que hoje compõem sua população e que fazem do Canadá um dos países mais multiculturais do mundo.

Em relação aos acadianos do Canadá, pode-se dizer que hoje são a maioria da população do Nouveau Brunswick bem como minoria na Nouvelle-Écosse, Québec, Ontario e Ile PrinceÉdouard. Esse povo cultiva e mantém viva sua herança cultural, através de símbolos nacionais e identitários: uma bandeira, um hino nacional, insígnia e divisa. Comemora a "Festa dos Acadianos" no dia 15 de agosto, promove Congressos mundiais ( o primeiro foi em 1994 e há um previsto para agosto de 2009), além de manter viva sua história através do Museu Acadiano da Universidade de Moncton, de livros e sites na internet. ${ }^{30}$

$\mathrm{O}$ relato de Émile Lauvrière sobre as desventuras dos acadianos nos esclarece diversos episódios da história do continente

${ }^{28}$ Cf. WEINMANN; CHAMBERLAND. Littérature québécoise: des origines à nos jours, p. 138.

${ }^{29}$ Para mais detalhes sobre a sociedade quebequense, ver GAGNON. Québec: estado e sociedade.

${ }^{30}$ Alguns sites sobre a Acadie e sua cultura estão disponíveis em: http:<//cyberacadie.com>.; http://fr.wikipedia.org/wiki/Peuple_acadien e http://lestudio1.com/Acadiens.html $>$. 
americano, em especial, a situação delicada que se estabeleceu entre os grupos francófonos e anglófonos do Canadá. Como esses acontecimentos são praticamente desconhecidos no âmbito dos estudos românicos, lembro-me das palavras de Paul Ricœur, citadas em epígrafe neste trabalho, esperando que este artigo contribua para "uma política da justa memória".

Résumé: Ce travail porte sur trois articles de l'historien français, Émile Lauvrière, ayant pour sujet l'Acadie, la plus ancienne colonie française de l'Amérique du Nord, publiés dans la Revue de l'Amérique latine, en 1924. Dans les deux premiers textes, l'auteur raconte l'histoire de la colonie, depuis sa création jusqu'à l'expulsion définitive des Acadiens par les Anglais et leur dispersion dans plusieurs régions de l'Amérique. Dans le dernier article, Lauvrière révèle l'existence de divers groupes d'Acadiens actifs au Canada et aux États-Unis. Il fait également des remarques sur la situation du Canada pays divisé entre les anglophones et les francophones - et il propose une plus grande intégration entre les pays de l'Amérique latine. De 1924 jusqu'à nos jours, de grands changements se sont opérés: les Québécois jouissent aujourd'hui des mêmes conditions de vie que les Canadiens des autres provinces et le peuple acadien cultive et garde vivant son héritage culturel.

\section{REFERÊNCIAS}

GAGNON, A.-G. (Org.). Québec: estado e sociedade. Trad. Zilá Bernd et al. Porto Alegre: Editora UFRGS, 2003.

LAUVRIÈRE, É.. L'Acadie et l'Amérique latine (I). Revue de l'Amérique latine, Paris, v. VII, n. 27, p. 193-202, mar. 1924a.

LAUVRIÈRE, É.. L'Acadie et l'Amérique latine (II). Revue de l'Amérique latine, Paris, v. VII, n. 28, p. 316-327, avr. 1924b. 
LAUVRIÈRE, É. L'Acadie et l'Amérique latine (III). Revue de l'Amérique latine, Paris, v. VII, n. 29, p. 401-406, maio 1924c.

LAUVRIÈRE, É. La tragédie d'un peuple. Paris: Librairie H. Goulet, 1924d. 2 v.

RICCEUR, P. A memória, a bistória, o esquecimento. Trad. Alain François et al. Campinas: Editora Unicamp, 2007.

WEINMANN, H.; CHAMBERLAND, R. Littérature québécoise: des origines à nos jours. Montréal: Hurtubise, 1996. 